\title{
Determinants of Spreads on Sovereign Bank Loans: The Role of Credit History ${ }^{*}$
}

\author{
Peter Benczur $^{\mathrm{a}}$ and Cosmin llut ${ }^{\mathrm{b}}$
}

December 2006

\begin{abstract}
This paper is an empirical investigation into the role of credit history in determining the spread on sovereign bank loans. It employs an error-in-variables approach used in rationalexpectations-macro-econometrics to set up a structural model that links sovereign loan spreads to realized repayment behavior. Unlike the existing empirical literature, its instrumental variables method allows for distinguishing a direct influence of past repayment problems (a "pure reputation" effect) from one that goes through increased default probabilities. Using developing country data from the period 1973-1981 and constructing continuous variables for credit history, we find that past default is a significant determinant of the spread, even after including country fixed effects. Moreover, its reduced-form effect is very similar to its structural form effect, indicating that most of the influence of past repayment problems is through the reputation channel. Overall, reserves to imports, past and predicted future default are substantial determinants of sovereign bank loan spreads.
\end{abstract}

JEL Classification Numbers: F30, F34, G12, G14, G15

Keywords: reputation, sovereign bank loan spreads, default risk, rational expectations.

\footnotetext{
* We thank Larry Christiano, Gábor Kézdi and seminar participants at MNB, Northwestern University and Bank of Spain's Workshop on Emerging Markets for helpful comments and suggestions. Part of the work was done while Ilut was a visiting scholar at MNB. All remaining mistakes are ours.

${ }^{a}$ Magyar Nemzeti Bank (MNB) and Central European University, email: benczurp@mnb.hu

b Northwestern University. Corresponding author, email: c-ilut@northwestern.edu
} 


\section{INTRODUCTION}

The absence of a well established bankruptcy code, the limited access to borrower's collateral and a lengthy, costly restructuring process drive a wedge between sovereign and corporate debt. These determine Eaton and Gersovitz (1981) to conclude that the binding constraint on sovereign debt repayments is generally a country's willingness to pay rather than its ability to pay. The question then arises as to what incentives a sovereign borrower has to repay its debt. From various repayment reasons (like seizure of overseas assets, direct sanctions, default signaling bad economic fundamentals and thus worsening borrowing terms), this paper is concerned with reputation. That particular mechanism means that countries with poor repayment reputation may see their subsequent access to world credit markets impaired, and this impairment reduces their welfare.

The effect of reputation could be addressed in terms of two punishments, a quantity (denial of a loan or credit ceiling) versus a price one (higher cost of borrowing). The literature on the first issue treats the penalty of default in terms of exclusion from future access. Since exclusion has essentially never been permanent, the focus has shifted towards understanding more the price punishment. The general conclusion is that a negative repayment history can raise the spread on sovereign debt through two main channels. The first is an increased default probability, which is either affected endogenously by past default or just signaled by it. The second is the punishment surcharge imposed by lenders, which is not related to default risk, and could be referred to as a "pure reputation" effect. The existence of this type of impact is the basic assumption for the theories that analyze reputation as a sole repayment incentive.

Whether credit history is an important repayment incentive remains mostly an empirical question. In this respect, the largest part of previous research has analyzed the pricing of sovereign loans. The most frequent empirical research approach has assumed only one source of risk (default) and postulated two relationships: one between the spread and the probability of default, and the other between the probability and economic fundamentals. The basic method was to substitute the second equation into the first and thus to obtain a reduced-form type of relationship between the spread and fundamentals. ${ }^{1}$ This literature has found past default as a determinant of debt prices, but has been unable to properly address the question of how such an effect arises.

The purpose of this paper is to contribute to this empirical literature in two major aspects. First, and most importantly, it focuses on the distinction of any direct effect of a "bad" repayment history on spread, above the indirect one going through increased default probability. Second, different econometric techniques and variables are used in order to

\footnotetext{
${ }^{1}$ See for example Edwards (1986), Ozler (1993), Eichengreen and Mody (1999), Easton and Rockerbie (1999).
} 
control for country heterogeneity (fixed effects), a problem that is important in the framework of this analysis, and has not been thoroughly dealt with in most of the previous research.

The data on spreads is from the World Bank's publication "Borrowing in International Capital Markets" for the period 1973-1981, on 46 developing countries. While most of the variables utilized in the paper are those suggested by the literature, we create continuous measures of past and future default, which are based on arrears data from the World Bank's Global Development Finance. Unlike the credit history indicators of Ozler (1993), these variables are compatible with country fixed effects.

The main estimation strategy used in the paper is a structural asset pricing approach. ${ }^{2}$ The starting point is that the spread is determined by expected default risk. Then, like in the errors in the variables method, we replace the expectation term with the realization of the default event and instrument the latter with information available at the time of pricing, which is given by the debtor's characteristics, including credit history. Overidentification receives a central role: it tests whether information affects the spread only through predicted default or there is an extra channel of influence. This setup identifies the risks priced by the market and offers a structural interpretation for the influence of the borrower's characteristics.

In the reduced form estimation, we find that both recent and distant default history have a significant positive influence on the spread, but the inclusion of country fixed effects is necessary. The conclusion of our benchmark structural specification is that future default risk, recent default history and an extra term, given by reserves to imports, can robustly and meaningfully describe the spread. Also, our instruments are relevant and valid. The structural form estimation provides statistical and economic evidence of a direct, "pure reputation" effect of recent default history.

The structure of the paper is the following: the second section comprises a review of the literature on the role of reputation. The next part explains the empirical strategy of the structural asset-pricing setup. The description of data and variables is presented in the fourth section. The fifth part discusses the main econometric problems related to estimation and describes the reduced- and structural-form results, while the last one concludes.

\section{RELATED LitERATURE}

\subsection{Theoretical models}

The effect of credit history on the sovereign debt market has been analyzed quite extensively in the theoretical literature. In general, one can distinguish two channels through which credit history affects the sovereign debtor. One is what could be called a "pure

\footnotetext{
${ }^{2}$ As in Benczur (2001).
} 
reputation" effect and the other the increased probability of default. The first one means an increase in spread or a denial of a loan without any implication coming from the future default probability. There are several lines of research that obtain this "punishment" result.

One, pioneered by Eaton and Gersovitz (1981), points to the need for the borrower to access the credit markets repeatedly as a motivation for a sovereign borrower to repay their debts. In these models, the sovereign borrower will be excluded from the world credit market once they repudiate their debt obligations. A more relevant theoretical contribution from the perspective of our paper is that of Wright (2002). He proves that if one considers the possibility of syndicated loans, in which each bank has a share of the profits, then each bank's incentive to maintain a good reputation in this cooperation makes them tacitly collude in punishing a country in default.

Literally speaking, there is no default along the equilibrium path in these models. Our repayment indicator, however, is arrears, which we view as an "early warning" indicator of outright default in the near future. Creditors can then signal their willingness to exercise the exclusion punishment by raising prices in response to going into arrears.

There is also a micro-finance literature that usually analyzes two types of borrowers, whose identities are their private information. For example, Eaton (1996) employs this approach for a sovereign debtor. The overall conclusion is that there are equilibria in which the defaulters pay more in interest or are denied loans.

The other channel is that past repayment problems are either simply a signal of a future default problem or will endogenously imply a higher default probability. For example, an approach to understand default costs is that governments repay their sovereign debt to affect agents' expectations about the fundamentals of the economy (Sandleris, 2004).

One can use also a dynamic model of sovereign borrowing to examine optimal consumption and default strategies. The dynamic perspective allows the study of the effect of credit history, given the need to reenter the credit markets in the future. This approach is followed by, for example, Yue (2005), and Kovrijnykh and Szentes (2005).

Accounting for the two possible channels of influence is essential for understanding "reputation" as a repayment incentive. If past default increases the spread through a higher probability of future default, and hence, lowers the probability of repayment, then the expected repayment is not altered. In this case, "reputation" cannot represent a repayment incentive. Only if past default would increase the spread on top of raising the probability of future default, would the expected repayment get higher and maintaining a "good reputation" would be a reasonable incentive to repay.

\subsection{Review of empirical literature}


There is some direct evidence on the repayment incentives of a sovereign debtor. Conklin (1998) finds extensive evidence consistent with sanction-based theory in his analysis of the lending behavior by a Genoese-led cartel to Philip II of Spain (1556 - 1598). According to the author's estimate, the King's observed debt ceiling, the cost of enduring the penalty and its ability to repay are all consistent with the predictions of Bulow and Rogoff (1989). On the other hand, English (1996) reached the opposite conclusion based on his analysis of American states' default during the 1840's.

The more relevant issue for our discussion is how a country's credit history affects the borrowing cost of a sovereign. The usual approach has been to assume only one determinant of the spread (default risk), postulate a relationship between the spread and the probability of default, and another between the probability of default and economic fundamentals. Merging the two equations, one gets a reduced-form relationship between the spread and the fundamentals. This approach has been the base of a very wide empirical literature that analyzes the pricing of bonds and bank loans, both for developing and developed countries. ${ }^{3}$ Among these, a few studies include a variable that reflects credit history. For example, Eichengreen and Mody (1999) use data on 4500 loans over the 1991-1997 period and employ a pooled OLS regression, corrected for sample selectivity. They notice that the history of rescheduling has a weak positive effect on the probability of an issue while it significantly increases the spread that successful issuers pay.

An important contribution to the issue of reputation is Ozler (1993), which has been cited by many theoretical papers as the main evidence of an effect of repayment history on credit terms. ${ }^{4}$ She uses data on 64 countries for the period 1968-1981, which was one of rapid international lending expansion. The econometric technique is a pooled OLS regression with time-specific dummies. Her main results are that the spread is influenced by more recent repayment history (which she identifies as the 1930s through 1960s), but not by distant history (before 1930).

Reinhart et al (2003) is a recent documentation of the effect of repayment behavior on sovereign debt. Employing a cross-sectional regression with multiyear averages of measures for default risk, history of repayment, inflation rates and external debt as controls, they find that a history of defaults weakens a country's ability to borrow large amounts on reasonable terms, because a bad credit history is reflected in lower creditworthiness (proxied by the country's credit rating).

Our analysis departs from that of Ozler (1993) and Reinhart et al (2003) in two major ways. The first one concerns the treatment of country fixed effects. By including time invariant variables like dummies for repayment problems, Ozler can no longer have country fixed

\footnotetext{
${ }^{3}$ See for example Edwards (1986), Ozler (1993), Eichengreen and Mody (1999), Easton and Rockerbie (1999).

${ }^{4}$ See for example Eaton (1996) or Obstfeld and Rogoff (1996, p.379)
} 
effects. We resolve this issue by constructing a continuous measure of recent default, which allows us to use both country fixed effects and default history indicators.

The second, more important contribution is a structural and causal empirical approach. The traditional framework cannot succeed when there is more than one determinant of the spread (besides default risk). More importantly, it is unable to identify the causal reasons why a fundamental affects the spread. Furthermore, it relies on two restrictive assumptions about the functional form of the relation between the spread and the risk probability and that between the risk probability and economic fundamentals. From these two, we relax the functional form assumption on the default prediction equation.

The inability to distinguish between different channels of influence is particularly important for the credit history case. As underlined in the review of the theoretical literature, there are two ways in which history could affect the spread. Looking only at the reduced-form results - as Ozler (1993) and Reinhart et al (2003) do -, one cannot separate the two effects.

\section{THE EMPIRICAL STRATEGY: A STRUCTURAL ASSET PRICING REGRESSION}

The starting point in the asset-pricing decision is that the spread reflects perceived risks. Estimating such a specification involves unobserved expectations of the risk(s) based on information at the time of pricing. Mainly three solutions have been adopted to overcome this issue. One widely used approach has been to assume specific functional form relations between the spread, the risk probability and the economic fundamentals to get, by substituting one into the other, an estimable reduced form equation. Another solution has been to use proxies for the probabilities, like credit ratings (see for example Kamin and von Kleist, 1999). A third approach has been to use multiple issues of the same borrower, assuming the same default probability (Cumby and Pastine, 2001). All these methods suffer from a common problem: they cannot identify more than one source of risk and test for a systematic extra effect of certain country characteristics.

Benczur (2001) suggests a rational expectations approach and proposes the errors in variables method (EVM) as a solution for these problems. According to EVM, one can replace in the pricing equation the expectations of the risks with their realizations. This will imply a correlation between the actual realizations and the errors. With the assumption of rational expectations then the actual realizations can be instrumented with any set of information available at the time of pricing.

More formally, ${ }^{5}$ one can start from the representation of the structural form of the pricing equation:

\footnotetext{
${ }^{5}$ See Benczur (2001) for further details.
} 


$$
s=\alpha+\beta R+\lambda_{1} E\left[r_{1} \mid Z, R\right]+\ldots+\lambda_{n} E\left[r_{n} \mid Z, R\right]+\varepsilon_{1},
$$

where $s$ is the spread, $Z$ contains information available at the time of pricing, $R$ is the benchmark interest rate, and $r_{1}, \ldots, r_{n}$ are future risk variables, like default risk. The spread is measured as the difference between the interest charged for the loans of a particular country and the benchmark world interest rate.The paper will include in the main specification only default risk as a rationally expected variable. Let $p_{i t}=E\left[d_{i t} \mid Z_{i t}, R_{t}\right]$ denote the conditional probability that, as of information available at the time of pricing $\left(Z_{i t}\right.$ and $\left.R_{t}\right)$, country $i$ does not fully repay its outstanding bank loans in the future (neglecting the possibility of a selective default). Then our basic specification for the spread is as follows:

$$
s_{i t}=\alpha+\beta R_{t}+\lambda E\left[d_{i t} / \mathrm{Z}_{\mathrm{it}}, \mathrm{R}_{\mathrm{t}}\right]+\varepsilon_{1 \mathrm{it}}
$$

The linear term can be derived from risk-neutrality and profit maximization, and assuming partial default on the principal $(x)$ but not on the interest: $(1-p)(1+r)+p(x+r)=1+R$, which implies $r-R=p(1-x)$.

According to the EVM method, one replaces the expectation term in (2) with its realization, given the rationality assumption:

$$
d_{i t}=E\left[d_{i t} \mid R_{i t}, Z_{i t}\right]+\varepsilon_{2 i t},
$$

where $Z_{i t}$ is the information set of country and world fundamentals, available at the time of pricing. Thus, they usually correspond to data from year t-1 and earlier. Also, given rational expectations, $E\left[\varepsilon_{2 i t} \mid R_{i t}, Z_{i t}\right]=0$. Then equation (2) becomes:

$$
s_{i t}=\alpha+\beta R_{t}+\lambda E\left[d_{i t} \mid R_{i t}, Z_{i t}\right]+\varepsilon_{1 i t}=\alpha+\beta R_{t}+\lambda d_{i t}-\lambda \varepsilon_{2 i t}+\varepsilon_{1 i t} .
$$

Now, $d_{i t}$ is not orthogonal to the compound error term, since it is not orthogonal to $\varepsilon_{2 i t}$ (prediction error) and $\varepsilon_{1 i t}$ (possible simultaneity problem). But according to the EVM approach, one can use the information set $\left\{R_{i t}, Z_{i t}\right\}$ as valid instruments, since it is correlated with the default event (from the prediction equation) and uncorrelated with the error term (from the rational expectations assumptions). Actually, as Wickens (1982) argues, this method provides consistent, but not fully efficient, estimates even when the information set is incomplete or the functional form of the prediction equation is unknown. This is a major advantage given the problems in applied research of assumptions about the functional form, selectivity bias and omitted variables. The key element is whether the fundamentals are correlated with the default variable. If they are, then they can be used as valid instruments in the pricing equation, without having to specify the default prediction equation.

By using a set of instruments larger than one (the number of risk factors in general), an overidentification situation arises. A rejection of this overidentification test could imply 
different conclusions. It might be that the rational expectations and risk neutrality assumptions are rejected. Or maybe the risk choice was the right one, but its indicator was imperfect. Our approach is that the instruments are proxying for a missing term in the structural equation, which is due to the direct effect of some factor on the spread, above the one coming from the influence on the predicted probability. This would mean replacing (4) with the following modification:

$$
s_{i t}=\alpha+\beta R_{t}+\lambda d_{i t}+\theta X_{i t}-\lambda \varepsilon_{2 i t}+\varepsilon_{1 i t},
$$

where $X$ is an added RHS variable. Then, there are two important points to check: first, whether, compared to equation (4), $X$ has to be included as extra RHS variable to restore the acceptance of overidentification. Second, whether the estimated $\theta$ is significant. The two points ought to be connected, but it is possible that only one of the indications is present in small samples.

\section{DATA AND VARIABLES}

The description of data and, more importantly, the definition of variables are of large signifiance, because this paper employs some indicators that are different from the literature. This section explains their motivation, construction and limitations.

The choice of the time period was partly driven by Ozler's (1993) observation that a period of market expansion is needed to distinguish the impact of an individual borrower's repayment history from the impact of a widespread panic. Thus, we use the period 19731981, which witnessed particularly intense syndicated bank lending to sovereign borrowers. The initial dataset contains information on 757 commercial bank loan contracts to 46 developing countries and were obtained from various issues of the World Bank's "Borrowing in International Capital Markets". 6

Since the economic fundamentals are mostly available at the annually frequency, we constructed yearly measures for the spread. Just like Easton and Rockerbie (1999), we used a weighted average of the original spreads, using as weights the loan quantities and maturities:

$$
\bar{s}_{i t}=\frac{\sum_{i=1}^{k} s_{i t} q_{i t} m_{i t}}{\sum_{i=1}^{k} q_{i t} m_{i t}}
$$

where $s_{i t}, q_{i t}$, and $m_{i t}$ denote the spread, loan quantity, and maturity of the ith loan contract for one country during one year. Edwards (1986) and Ozler (1993) used only the loan quantity.

\footnotetext{
${ }^{6}$ Data on fees and commissions are not reliably available. It is noted, however, that these costs are low relative to the spreads (see Edwards, 1986).
} 
Using maturity in the weighting allows for taking into account that the spread of a longer maturity debt influences average credit terms to a larger amount than the spread of a shorter maturity loan. This transformation means that we are left with 252 yearly observations and an unbalanced panel. ${ }^{7}$

Data availability further reduces the working sample. Arrears data, used for our default measures, is available only for 38 countries, resulting in 206 observations. Other country fundamentals are also not available for some countries, and the use of first lags, which turns out to be essential throughout the paper, means that one observation from each country is lost. This reduces the sample to 158 observations from 38 countries. Finally, the smallest and largest values of our constructed variables are quite unrealistic, thus we excluded the top and bottom $1 \%$ for the recent default and $2 \%$ for the future default variable. The final sample for which we report the results is 150 observations and 37 countries.

Graph 1 illustrates the evolution of the sovereign spreads in the sample, together with the BAA-rated US corporations bonds' spread (taken from the Federal Reserves' website). This comparison shows that sovereigns pay similar spreads than BAA-rated US companies. Another aspect is that the variation in spreads during the sample seems to be constant, with two exceptions: for 1975, where the variation is very small, and in 1981, where it is large. This latter point is interesting because it suggests that commercial banks were distinguishing between the borrowers, even before the "unexpected" debt crisis of 1982.

\section{Past and future default variables}

We differentiate between a "distant" and a "recent" default history. There are reasons to believe that recent history matters more, or at least as much, as the more distant one. Indeed, Ozler (1993) finds that repayment difficulties happening before the 1930s did not significantly matter for spreads in the 1970s, while those afterwards did.

For "distant" history we use two indicators. One includes the presence of default or rescheduling of bank loan debt to official creditors in the period 1940-1970. This dummy variable was constructed by recording a ' 1 ' whenever there was a repayment problem indicated in two sources: in Ozler (1993), which includes data for 1956-1968, and Lindert and Morton (1989), which refers to the period 1940-1970. The second dummy variable is more exhaustive and adds to the first one by including any repayment difficulties on bonds during 1958-1967 (source: Ozler, 1993). Given that we analyze the bank loan debt, we are inclined to use more the first indicator, which in fact is also the one that gives more robust and conclusive results.

Table 1 presents some of its basic summary statistics, the number of observations and countries that had past repayment problems. It is important to note that the indicator has

\footnotetext{
${ }^{7}$ In fact the correlation between the variable using the maturity and quantity as weights and the one using only
} 
significant variation to be able to identify the effects. The mean for this variable is high, and shows that around $30 \%$ of the countries in the sample had some repayment problems during 1940-1970.

While these indicators are very similar to those used in Ozler (1993), the indicators reflecting "recent" history are our own contribution. Besides our a priori view that recent defaults should have larger importance, this indicator allows including a continuous variable instead of a dummy to reflect past repayment behavior, enabling to control for country fixed effects and still include a default history measure. We construct this indicator from data on debt arrears (both interest and principal) on long-term debt outstanding, available since 1971 from the Global Development Finance CD-ROM.

The use of arrears to define a payment problem is reasonable but subject to one important qualification. One might argue that data on repayment reschedulings should also be included. There are many reasons why we still stick to arrears. The first is the lack of data on rescheduling arrangements in this time period. Second, as Cline (1984) notes, debt reschedulings are usually preceded by the accumulation of arrears on debt payments. This implies that reschedulings are only important to the extent that they take place independently of arrears. Third, most of the theoretical models on the pricing of sovereign debt use arrears as indicator for the repayment history.

The indicators for recent default history are computed using the following steps:

1. For each country we use the time period 1971-1981 and for each of these years, we compute the flows of private arrears (on interest and principal). ${ }^{8}$ Let this measure be denoted by arrears $j_{j t}$, where $j=1, \ldots, 37$ for countries and $t=1, \ldots, 11$ (corresponding to the period 1971-1981).

2. For the same balanced panel coverage we compute the following indicator:

$$
\text { recentdef } 10_{j t}=\sum_{k=1}^{t} \operatorname{arrears}_{j(t-k)} *\left(1-\frac{k-1}{10}\right),
$$

for each country $j=1, \ldots, 33$ and each $\mathrm{t}=1, . ., 11$ with $\mathrm{t}_{0}=0$ (for year 1970). Thus it is an indicator for the discounted repayment problems of the last 10 years.

What this formula actually does is, for each year, to add the variable arrears $s_{j t}$ starting from the first lag and going back until 1970. The addition of these past values is weighted by decreasing coefficients $(1,0.9, \ldots, 0.1)$. This takes into account a "memory" that is fading in time, such that more distant events have a relatively smaller importance for the present than the more recent ones. ${ }^{9}$

the latter is close to 1 , so the results change very slightly by using one of them.

${ }^{8}$ We use the following data series: DT.IXA.DPPG.CD for interest arrears and DT.AXA.DPPG.CD for principal arrears.

${ }^{9}$ We tried various additional ways of cumulating arrears: not using these coefficients at all, or instead using a different functional form, like a quadratic decay. In general, the results did not change. 
A further step could be taken to separate the effects of recent history. One might argue that a closer repayment problem would influence the spread only indirectly, through increased default probability, since it is very likely to reflect problems that could generate future defaults. On the other hand, a more distant default is expected to affect directly the spread, through a punishment surcharge. Also, there might be a "grace" period applied when the banks decide whether to charge higher spreads for defaulting countries. Thus, we separated the ten years measure into the last three years and the preceding seven. The first choice was not significant even in the reduced form, leading us to believe that there was indeed a grace period attached to previous defaults. The variable that added the flows of arrears from time t- 4 to $\mathrm{t}-10$ however was significant and it is the one reported in our results section.

We would stress that there is no clear indication from theory regarding the choice of the repayment history variable. In particular, one could also employ a similar measure based on arrears normalized by the amount outstanding. That strategy, however, does not yield plausible estimates, which we take as an indication that the absolute measure captures repayment history better.

We construct our future default measure by using again the GDF data on debt arrears. This variable should reflect the realization of the proportion of losses for a loan offered. As demonstrated by Sturzenegger and Zettelmayer (2006), precise measures of realized repayments are very hard to compute for sovereign loans. Our strategy is to employ a reasonable proxy: we add the arrears for a period similar to the average maturity. As opposed to our measure for recent default, this sum needs to be normalized by the total loan amount corresponding to that observation, in order to reflect relative losses. Since we are analyzing private markets (and private lending was dominant in that period) we include again only the private arrears in the default indicator. ${ }^{10}$

Let us denote the yearly GDF data on arrears by $X_{i s}$, with $s$ ranging from 1970 to 1989. As those arrears may refer to contracts from multiple years, we need to allocate them among contracts. Our approach involves the following steps. First, we split $X_{\text {is }}$ among contracts from years $s-1, s-2, \ldots s-8$ in proportion to new disbursements in the corresponding year: $Y_{i s, s-j}=X_{i, s} N D_{i, s-j}\left(N D_{i, s-1}+\ldots N D_{i, s-8}\right), j=1 \ldots 8$ (the average loan maturity in our sample). Here $Y_{i s, s-j}$ is the time $s$ arrears on a time $s-j$ contract and $N D_{i, s-j}$ is the size of the time $s-j$ loan for country $i$. Then we cumulate the arrear fragments $Y_{i t+1, t}, Y_{i t+2, t} \ldots Y_{, i t+8, t}$ into which a time $t$ contract goes over its lifespan: $D_{i t}=Y_{i t+1, t}+Y_{i t+2, t}+\ldots+Y_{i t+8, t}$.

Thus, in order to recover these amounts we split the arrear flows $X_{i s}$ among the preceding loans by assuming that larger loans were more likely to go into arrears. We motivate this splitting of cumulated arrears by two arguments: one is that there is hardly any

\footnotetext{
${ }^{10}$ Although robustness checks were made adding official arrears.
} 
information available on how these arrears were truly obtained and how to disaggregate it; second, assuming that these flows can be attributed to several preceding loans is consistent with the cross-default clauses that these contracts included. According to such clauses once a country enters into default or any repayment problems that constitute a break on the contract with one lender, this will be treated as default also by the other creditors. Alternatively, instead of using loan quantities as weights, we experimented with equal weights and the results were robust. We also considered the effect of the grace period, thus excluding from this summation the average grace period of 3 years. All these had led to very similar results.

Table 2 provides some brief descriptive statistics of our benchmark choice for future and recent default. For recent default around $65 \%$ of the observations are equal to 0 for both the full and the reduced sample; this number is around $20 \%$ for the future indicator. The difference is due to more frequent arrears after 1981, but it shows that there were still countries that were not accumulating arrears in this period.

\section{Economic fundamentals}

An important part of the estimation is to properly control for other factors, including here the economic fundamentals. The sources for this category of variables were Global Development Finance, International Financial Statistics and World Development Indicators. In choosing these factors, given also the data availability, we are following most of the literature in considering the following variables: debt to GDP, reserves to imports, debt service to exports, current account per GDP, exports to GDP, growth of per capita GDP, growth of gross investment, GDP per capita, inflation, credit to private sector per GDP.

In addition to these, we constructed two more variables that could depict other important factors. Repeated borrowings are designed to capture the importance of relationship banking. It is constructed by cumulating the number of months in which the borrower received loans. ${ }^{11}$ Proportion of countries with arrears in the region captures a regional contagion effect from one country going into arrears. It is constructed by dividing the number of countries with arrears from the same region by the total number of countries in that region. Finally, for the benchmark interest rate we use the LIBOR USD 1-year rate.

\section{ESTIMATION ISSUES AND RESULTS}

Both the reduced and the structural form specification are subject to two major econometric problems: the need to control for country-level heterogeneity (fixed effects), and

\footnotetext{
${ }^{11}$ An alternative measure would be the number of years in which the borrower received loans; however that variable turns out to be less significant, probably given the inherently lower variation compared to the benchmark one.
} 
the validity of the strict exogeneity assumption. We explore these issues for the reduced form first, and then proceed to estimate the relevant specifications for the structural form.

\subsection{The reduced form}

The reduced form in a panel framework is:

$$
S_{i t}=\alpha+\beta R_{t}+\Gamma Z_{i t}+c_{i}+\varepsilon_{i t},
$$

where $\varepsilon_{i t}$ is the idiosyncratic error term, $Z_{i t}$ are the economic fundamentals for country $i$ known at time $t$ and $c_{i}$ is the unobservable individual effect.

The first major concern is that the usual pooled OLS estimates are incompatible with individual country effects. Unfortunately, the fixed effects (FE) estimation or first-differencing (FD) makes it impossible to include time-invariant variables, like the distant default dummy. This is important in our case because the estimated coefficient on the distant default dummy in a pooled OLS regression might be picking up the missing country fixed-effect.

In this case, the comparison of the distribution of country effects across groups with different default history might convey some information. Indeed, the results from the reducedform estimations suggest that defaulters (categorized through the distant default dummy) are being charged significantly higher spreads. The difference between the means of the two groups is 0.3 , which is around one and half times the estimate on the default dummy (see Table 3). Moreover, the standard deviation of the country fixed effects is 0.3 ; hence it could be argued that the estimated default dummy explains around $70 \%$ of the typical variation of the country fixed-effects.

The particular results of the reduced-form estimation are presented in Table 3 and refer to four specifications. The recent default variable used is the "t-4" private arrears flows, weighted by linearly decreasing weights. As Column (1) shows, most of the explanatory variables are significant and have the expected sign in the pooled OLS specification. When running panel data specific regressions like fixed effects (Column 2) and random effects (Column 3), some of the results change; indicating that country fixed effects do affect some variables. $^{12}$

A key assumption behind the FE and RE is strict exogeneity, which requires that the idiosyncratic error terms, conditional on the individual effect, are uncorrelated with past, present or future values of the regressors. If this fails, then all the classic panel data methods and specification tests are inconsistent. Formally, the strict exogeneity assumption

\footnotetext{
12 The debt to GDP ratio variable is different in this respect: when an OLS estimation is run, it is positive and significant, but whenever a panel data method is used (like FE, RE and a better specified estimation as the instrumented first difference as in Column (4) ) it becomes highly insignificant. We interpret that as the combined effect of the country effects and small time variation.
} 
means: $E\left[\varepsilon_{i t}^{\prime} / Z_{i s}, c_{i}\right]=0$, for all $t$ and $s$. There are reasons to suspect that the assumption might fail, as any pricing error $(\varepsilon)$ could affect the future values of some indicators, like reserves, debt to GDP, participation on the market, proportion of countries in arrears.

Wooldridge (2002) suggests a test for this: use the FE estimator but also include future values of some variables that are likely to break the assumption. Their significance is evidence that the assumption is likely to fail, at least for those variables. When performing such a test, we do actually find that when we include leads of variables such as: proportion of countries with arrears, experience on the market, saving to GDP, debt to GDP, they are significant. It is worthwhile mentioning that the strict exogeneity assumption is likely to be satisfied or having a small inconsistency effect for our recent default variable since it captures arrears happening at time $t-4$, thus it is insulated from the present time $t$ through time $t+3$ pricing error. Given the economics behind the regressions, the assumption of the strict exogeneity is nevertheless questionable for many variables.

When there are concerns about strict exogeneity, the general approach is to use a transformation to remove the country effects $c_{i}$, and then search for instrumental variables, assuming only sequential exogeneity (Wooldridge, 2002). According to the this assumption, the idiosyncratic errors, conditional on $c_{l}$, should be uncorrelated with the contemporaneous and past values of the regressors (instruments), but not with future values.

In this respect, a first-difference (FD) estimator is attractive:

$$
s_{i t}-s_{i(t-1)}=\beta\left(R_{t}-R_{t-1}\right)+\Gamma\left(Z_{i t}-Z_{i(t-1)}\right)+\left(\varepsilon_{i t}^{\prime}-\varepsilon_{i(t-1)}^{\prime}\right)
$$

One can notice that if strict exogeneity fails, then there is a problem here as well, since $E\left[\varepsilon_{i(t-1)}^{\prime} / Z_{i t}\right] \neq 0$. The sequential exogeneity assumption, however, implies that all the lags of $Z$ (or their linear combination) can be used as potential instruments for $\left(Z_{i t}-Z_{i(t-1)}\right)$ and then the estimation is consistent. Column (4) is an attempt for such an improved specification: the variables are first-differenced and the proportion of countries with arrears is instrumented with its first lag. ${ }^{13}$ The estimates' precision is again smaller, due to the fact that there is less timevariation and that by first differencing there is one observation not used for each country.

In conclusion, our findings suggest that fixed effects do play a role, that the strict exogeneity is a restrictive and unreasonable assumption for most of the variables (invalidating the classical panel data methods) but after controlling for these issues there are economic fundamentals, including recent default, that significantly influence the spread.

\footnotetext{
${ }^{13}$ The difference with the not-instrumented FD version is mostly with respect to the significance of this variable.
} 


\subsection{The structural form}

\subsubsection{Estimation issues}

As our reduced form results indicate the presence of fixed effects, we focus only on this case in our structural analysis. Equation (4) should then be written as

$$
s_{i t}=\alpha+\beta R_{t}+\lambda d_{i t}+c_{i}-\lambda \varepsilon_{2 i t}+\varepsilon_{1 i t},
$$

where $d_{i t}$ is instrumented with time $t$ information (Z). This might be estimated with the usual panel-data methods. However, the strict exogeneity assumption is much more problematic and crucial in the structural form than in the reduced form. As Keane and Runkle (1992) strongly point out, in this type of models, there are never any strict exogenous variables or instruments. This formal result comes from the effect of the prediction error on the future values of the variables. Given this problem, both FE and RE estimators are inconsistent. The solution is again to eliminate the individual effect, for example by first-differencing. This requires only the sequential exogeneity assumption.

This would mean estimating:

$$
s_{i t}-s_{i(t-1)}=\beta\left[R_{t}-R_{t-1}\right]+\lambda\left[d_{i t}-d_{i(t-1)}\right]-\lambda\left[\varepsilon_{2 i t}-\varepsilon_{2 i(t-1)}\right]+\left[\varepsilon_{1 i t}-\varepsilon_{1 i(t-1)}\right]
$$

However, the first difference specification causes further complications. The rational expectation assumption guarantees that the prediction error $\varepsilon_{2 i t}$ is orthogonal to time $t$ information, but this is not true about $\varepsilon_{2 i t-1}$. The remedy is to use $Z_{i(t-1)}$ or $Z_{i(t-2)}$ as instruments, as those variables are not correlated with any error at time $t$ or $t-1$.

If some variable, $X$, is believed to be part of the model as extra RHS variable, then equation (5) is to be first-differenced, and it becomes:

$$
s_{i t}-s_{i(t-1)}=\beta\left[R_{t}-R_{t-1}\right]+\lambda\left[d_{i t}-d_{i(t-1)}\right]+\theta\left[X_{i t}-X_{i(t-1)}\right]-\lambda\left[\varepsilon_{2 i t}-\varepsilon_{2 i(t-1)}\right]+\left[\varepsilon_{1 i t}-\varepsilon_{1 i(t-1)}\right] .
$$

Including extra RHS variables one could also worry about the possible failure of strict exogeneity for these variables. However, since in the benchmark specification these extra variables will be reserves to imports and recent default, for which we do not have reduced form evidence about the lack of strict exogeneity, we do not instrument them. Moreover, not instrumenting the extra RHS variables allows for a clearer and more direct comparison with the reduced form regression. Thus, whenever we refer to instrumenting in the structural-form we mean instrumenting only the future-default variable.

In conclusion, in the structural-form we use the first difference estimator with appropriate instrumenting: it eliminates the individual effects, and the right choice of instruments resolves the issue of the prediction error. The appropriate instruments include the first and second lags of the regular instruments (time $t$ information). Using as instruments the 
levels of the variables (as opposed to the second difference) leads to more precise estimates, but at the cost of making the direct comparison with the reduced-form results of Table 3 more difficult. ${ }^{14}$

The whole structural estimation framework is based on the validity of the instruments: they should be correlated with the instrumented variable and also uncorrelated with the error terms. In order to check for this, we report several measures that summarize the first-stage regression: the partial $R^{2}$ of the first stage regression, the $F$ test of the joint significance of the excluded instruments in the first stage regression; the Anderson canonical correlations likelihood-ratio test of whether the equation is identified, i.e., that the excluded instruments are relevant.

The validity of the instruments can be checked by testing their orthogonality to the residuals. As argued in Section 3, we interpret a rejection of the overidentification test as evidence for the misspecification of the model. Hence, the instruments that cause the rejection of overidentification should be included in the regression as extra RHS variables. There is a variety of choices for this test and we employ a test that will be appropriate in a setting with heteroskedasticity and autocorrelation. This is the Hansen's J statistic, which can be used either with IV or GMM, and it is consistent even with intra-cluster correlation. ${ }^{15}$

\subsubsection{Results}

Estimation in levels is plagued with several problems which render it unreliable. Besides the presence of the fixed effects and the failure of strict exogeneity, the level specification also suffers from a very significant rejection of the overidentification test. When using the FE or RE estimation the null hypothesis of the overidentification test is very strongly rejected no matter what other extra RHS variables are included (with the p-value being smaller than 0.001). Also, the instrumented future default risk appears very insignificant and the point estimate is much lower than the one resulting from the correctly specified first differenced estimation. We attribute these to the failure of the strict exogeneity assumption.

If instead we run the pooled level IV the results are broadly close to our benchmark first-difference specification: the instruments have a similar first-stage explanatory power, there are extra structural effects coming from recent default and reserves to imports ratio, with the latter two variables also improving on the overidentification test. When the past default dummy is included as an extra RHS variable, it is not significant and decreases the pvalue on the overidentification test. Thus, this specification would suggest that past distant

\footnotetext{
14 Though we believe that the first difference estimator is more suitable, we nevertheless performed various versions of IV on the pooled data in levels. Since these results are much less robust and meaningful, we do not report them in any details, but discuss them briefly instead.

${ }^{15}$ This feature is important because Baum et al.(2003) cite evidence that show that the presence of intra-cluster correlation can readily cause a standard overidentification statistic to over-reject the null.
} 
default affects the spread through future default risk, and not through a true reputation channel.

The advantage of the level specification is that the pooled level IV can separate the effect of distant default by channels. However, the overidentification test's p-value is still somewhat low, around 0.2 , and the estimates are questionable since the pooled IV regression ignores the country effects. Thus, given these problems, we would not trust enough this specification to make a strong conclusion; instead we look for a more definitive answer about the effect of the time-varying recent default indicator and use the instrumented first difference approach.

The results of our benchmark specifications are presented in Table 4. As motivated in Section 5.2.1 we choose as our main structural form estimation the one in first differences, since it provides the framework that allows us to make correct inference on the overidentification test and the RHS variables. . Overall, there are three important findings we would discuss: the influence of the future default indicator, the coefficient of the benchmark yield, and the channel decomposition. Starting with the first, the future default's point estimate is strikingly robust across all methods (being around 0.4 ), ${ }^{16}$ and in almost all of them significant at $10 \%$ level.

Although the mean of this indicator is just 0.15 , this is not very indicative of its influence, because the variance is large and for many countries the indicator's value is around 0.5 and even 1 . If we consider an increase in the indicator from its median to the $90^{\text {th }}$ percentile, then this would raise the spread by approximately 0.2. Consequently, the coefficient can be considered as sizable, as the sample mean of the spread is 1.35 . This is an important finding, because it suggests that the expected default risk was priced in the lending decision and that the debt crisis of 1982 was, to this extent, "anticipated". Nevertheless, it remains true that for many countries this prediction was correct mainly in sign, and less in the size, as the quantitative effect of the future default risk is small.

A second general conclusion is the large significance of the benchmark rate, which was also present in the reduced-form results. Actually, the most robust and significant result of both the reduced and structural form is the negative coefficient on the benchmark yield. Given that the spread is defined as the difference between the loan rate and the LIBOR rate, this result is equivalent to the finding that the loan rate responds less than one-in-one to the world interest rate (the reaction coefficient is around 0.9). This conclusion is found also in Eichengreen and Mody (1999), Benczur (2003) and Uribe and Yue (2005).

\footnotetext{
${ }^{16}$ The future default indicator is the 8 years measure of total private arrears divided by the loan amount. While running robustness checks for various sample sizes and instruments used we find that its point estimate ranges from 0.3 to 0.45 and that a reasonable mean of the estimates obtained is around 0.4 . The estimates of $0.36-0.4$ in Table 3 are part of the results we obtained throughout the process.
} 
The central results concern the channels of influence of the economic fundamentals, particularly that of the recent default indicator. The starting point is to use the benchmark yield and the future default indicator as the only explanatory variables, which is done in Column (1). The first-stage summary statistics indicate that the instruments are relevant, with a partial $\mathrm{R}^{2}$ of 0.08 and a value for the $\mathrm{F}$ test of the joint significance of the excluded instruments of 12. ${ }^{17}$ Also the Anderson canonical correlations likelihood-ratio test of whether the excluded instruments are relevant (the null being that the equation is underidentified) rejects the null with a $p$-value smaller than 0.01 .

However, the overidentification test does not offer strong evidence of a correct specification, with the $p$-value being 0.2 . Our strategy is to interpret that as the influence of some fundamentals (used as instruments) on the spread not going only through predicted default probability. Then, the next step is to look for variable(s) that could improve upon overidentification and/or be significant as extra RHS variables. Although these two criteria should give the same conclusion, the small sample implications might affect their power in detecting the right answer. The natural candidate is the recent default variable. Its inclusion gives the results displayed in Column (2): the p-value of the overidentification test increases to 0.3 , and the variable is very significant and has the right sign. ${ }^{18}$

While this might look like the final specification (given the specification tests) we still explore whether additional variables should be included. After a thorough search, we find that the reserves to imports ratio is such an additional variable: it has a positive, significant and robust coefficient and it considerably improves the overidentification result (the p-value becoming 0.47 , as in Column (3)). It appears then that both these extra RHS variables improve on the overidentification test. Thus, after running several robustness checks we interpret Column (3) as our benchmark specification for the structural form.

In terms of robustness, we found that many initial specifications were sensitive to a very small number of extreme outliers. The results presented here are, on the contrary, robust to most changes in the set of observations or instruments. The null of homoskedasticity in the regression of Column (3) is not rejected by the Pagan-Hall general test statistic ( $p$ - value of 0.36), which suggests that, given its inferior small sample properties, an asymptotically

\footnotetext{
${ }^{17}$ This value is higher than the one (equal to 10) considered in Steiger and Stock (1997) as a rule of thumb critical value for considering the instruments weak A more precise formulation of tests for weak instruments is done in Stock and Yogo (2002) where they tabulate critical values for the first stage F-statistic depending on different criteria including the number of instruments and level of relative bias compared to the OLS that one is ready to accept. The critical value for one endogenous regressor, 6 excluded instruments, a 10\% relative bias and a 5\% significance level of the test is close to 11 .

${ }^{18}$ Note that the first stage F-statistic for the excluded instruments decreases, but that is mostly because the added exogenous variable takes away (by construction it includes the lag of recent default, which is one of the excluded instruments) some of their significance. Also, note that the point estimate of the instrumented default risk is very similar when the extra exogeneous variable is included.
} 
efficient GMM is not needed. ${ }^{19}$ Also, there is no evidence for serial correlation of the errors in this first difference specification.

An interesting exercise is compare the point estimates from the reduced and structural form estimation for the extra risks. For the reserves variable, the estimated coefficient in the structural form is about $80 \%$ of that from the reduced form. We interpret this as evidence that this factor has some effect on the spread going through the expected default risk, but most of the influence is through a direct channel. For the recent default, the same comparison leads to the conclusion that its effect is almost entirely a direct one. ${ }^{20}$

In terms of size, the recent default measure does not appear to have a large economic significance: given that there were not so many countries in our sample that had a large amount of private arrears, it is not sprprising. Interestingly however, our analysis shows that this measure is statistically significant and in some cases economically too, as there are countries for which this extra "punishment" effect accounts for 35 basis points or more. For the reserves to imports ratio variable, the quantitative effect is more pervasive. An increase in the measure from its median to its $90^{\text {th }}$ percentile would increase the spread by 25 basis points (around $20 \%$ of the average spread).

These numbers suggest an order of magnitude from which we conclude that the "pure reputation" effect of the recent default history is a sizable determinant of the spread, as are the future default risk, benchmark interest rate and reserves to imports ratio. It is nevertheless true that for some observations the risks do not appear to be quantitatively significant and that there is a combination of a "constant" term commonly applied to all countries and country fixed effects that is important in the pricing of loans. These unidentified components might reflect other country characteristics such as the bargaining position that are not related to risks, or includes some of the risk effects that our measures are not able to pick up. Based on our specifications it appears that as countries worsen or improve on their risk factors there is an alteration in their credit terms but it is seems that this takes place significantly only for more considerable changes in risks.

The result that recent default has an extra effect on the spread could be interpreted in a different way from reputation: when a country accumulates arrears the banks try to recover some of their losses by charging a higher spread for that country. While we acknowledge that this is an effect that cannot be convincingly separated from our reputation interpretation, its plausibility hinges on the fact that the bank that offers new disbursements is the same that suffered losses in the past. We do not have the data to confirm that, but we believe that there were multiple banks that were offering loans. Moreover, even if this was the correct mechanism through which the spread increased, it has the same effect from the country's

\footnotetext{
${ }^{19}$ Even so, results from a GMM regression were found to be very close.

${ }^{20}$ In some estimations the reduced form point estimate is even lower than the structural form, but we interpret that as being an issue of the precision of the estimation.
} 
perspective: once it defaults it faces a higher cost of borrowing in the future, in terms of expected repayment, no matter whether this comes from a punishment strategy from the lenders, or it is the result of a systematic price increase.

Regarding the structural effect of reserves, we offer two interpretations. The first involves a systematic pricing error: either banks systematically overreacted to movements in reserves, or the countries themselves chose, ex post, to invalidate the expectations and defaulted less than anticipated. The second explanation views reserves to imports ratio as a proxy for a currency crisis risk. Such an event might imply a contagion from the local currency market to foreign currency markets, or investors may suffer a systematic decrease in their "risk-bearing ability" or willingness during currency crisis.

Summing up, we find that future default risk, recent default history and the reserves to imports ratio offer a robust and meaningful description of the spread. Also, our instruments are relevant and valid. Thus, the reduced-form influence of all variables but the benchmark interest rate, recent default and reserves can be attributed to their effect on the probability of default. Comparing the structural and reduced form estimates for these extra variables suggests that their effect on the spread goes almost entirely through a separate channel than the default likelihood.

\section{CONCLUDING REMARKS}

We extended the existing empirical literature on the role of credit history in sovereign bank lending along two dimensions. One is that we used a continuous measure of past (recent) default, enabling us to control for country fixed effects. Our other, more important contribution is the empirical strategy that allows for the distinction of multiple channels of influence. The framework, suggested in Benczur (2001), is a structural asset pricing rationalexpectations estimation, in which the spread may be influenced by multiple risks. Using the errors in the variables method, we replace the expectation term with its realization and instrument the latter with information available at the time of pricing. Using the overidentification test, we then investigate whether there is any instrument that should be added as an extra RHS variable. We interpret any such variable as influencing the spread not only through expected default risk, but having an extra effect on it.

The reduced-form estimation provides evidence that, after controlling for fixed effects, borrower and regional characteristics, both recent and distant repayment history are significant. This makes the result similar to that obtained by Ozler (1993) and concludes that although country effects do matter, there is a role of credit history in determining sovereign spreads. The structural-form regression provides strong evidence of an extra effect of credit history (a "pure reputation" effect), above that going through the predicted default probability. The major structural specification includes the benchmark LIBOR interest rate, the expected 
default risk, the recent default indicator and the reserves to imports indicator. All these variables are significant and robust to different specifications.

In terms of the default costs, we do believe that in reality there is a complex mix of trading and political sanctions, spillovers to other transactions and relationships, signaling and reputation considerations. Our main result is that there is evidence of the latter effect.

\section{REFERENCES}

Baum, Christopher F., Mark E. Schaffer, and Steven Stillman, 2003, Instrumental Variables and GMM: Estimation and Testing, Boston College, Department of Economics, Working Paper No. 545.

Benczur, Peter, 2001, Identifying Sovereign Bond Risks, Central European University Working Paper, Working Paper No. 9/2001.

Benczur, Peter, 2003, The Composition of Sovereign Debt: A Description, Central European University Working Paper, WP7/2003.

Cline, William, 1984, International Debt: Systemic Risk and Policy Response, Washington D.C.: Institute of International Economics.

Conklin, James, 1998,The Theory of Sovereign Debt and Spain under Philip II, Journal of Political Economy, Vol. 106, No. 3. pp. 483-513.

Cumby, Robert E., and Tuvana Pastine, 2001, Emerging Market Debt: Measuring Credit Quality and Examining Relative Pricing, Centre for Economic Policy Research, Discussion Paper no. 2866.

Easton, Stephen and Duana W. Rockerbie, 1999, What's in a Default? Lending to LDCs in the Face of Default Risk, Journal of Development Economics, 58, April 1999, pp. 319-332.

Eaton, Jonathan, 1996, Sovereign Debt, Reputation and Credit Terms, International Journal of Finance and Economics, Vol. 1, No. 1, pp. 25-36.

Eaton, Jonathan and Mark Gersovitz, 1981, Debt with Potential Repudiation: Theoretical and Empirical Analysis, Review of Economic Studies, Vol. 48, No.2, pp. 288-309.

Edwards, Sebastian, 1986, The Pricing of Bonds and Bank Loans in International Markets, European Economic Review, Vol. 30, pp. 565-589.

Eichengreen, Barry and Ashoka Mody, 1999, Lending Booms, Reserves and the Sustainability of Short - Term Debt: Inferences from the Pricing of Syndicated Bank Loans, NBER Working Paper no. 7113.

English, William B., 1996, Understanding the Costs of Sovereign Default: American State Debts in the 1840s, American Economic Review, Vol. 86, No.1, pp. 259-275. 
Keane, Michael P., and David E. Runkle, 1992, On the Estimation of Panel-Data Models With Serial Correlation When Instruments are not Strictly Exogenous, Journal of Business \& Economics Statistics, Vol.10, No.1, pp 1-9.

Kamin, Steven B., and Kartsen von Kleist, 1999, The Evolution and Determinants of Emerging Market Credit Spreads in the 1990s, International Finance Discussion Papers No. 653, Board of Governors of the Federal Reserve System.

Kovrijnykh, Natalia and Balazs Szentes, 2005, Competition for Default, University of Chicago, mimeo.

Lindert, Peter H., and Peter J. Morton, 1989, How Sovereign Debt has Worked, in Jeffrey Sachs, ed.: Developing Country Debt and Economic Performance, Volume I: The International Financial System (University of Chicago Press).

Obstfeld, Maurice, and Kenneth Rogoff, 1996, Foundations of International Macroeconomics, MIT Press.

Ozler, Sule, 1993, Have Commercial Banks Ignored History?, American Economic Review, Vol 83. No.3, pp. 608-620.

Reinhart, Carmen M., Kenneth Rogoff, and Miguel A. Savastano, Debt Intolerance, Brooking Papers on Economic Activity, Volume 2003, No.1, pp.1-70.

Sandleris, Guido, 2004, Sovereign Defaults: Information, Investment and Credit, Columbia University, mimeo.

Staiger, Douglas and James H. Stock, 1997, Instrumental Variables Regression with Weak Instruments, Econometrica, Vol.65, No.3, pp. 557-586.

Stock, James H. and Motohiro Yogo, 2002, Testing for Weak Instruments in Linear IV Regression, NBER Technical Working Paper 284.

Sturzenegger, Federico and Jeromin Zettelmayer, 2006, Creditors Losses versus Debt Relief: Results from a Decade of Sovereign Debt Crises, IMF, mimeo.

Uribe, Martín and Vivian Z. Yue, 2005, Country Spreads and Emerging Countries: Who Drives Whom?, Journal of International Economics, forthcoming.

Wickens, Michael R., 1982, The Efficient Estimation of Econometric Models with Rational Expectations, Review of Economic Studies, Vol. 49, No.1, pp. 55-67.

Wooldridge, Jeffrey, 2002, Econometric Analysis of Cross Section and Panel Data, Cambridge, MIT Press.

Wright, Mark L.J., 2002, Reputations and Sovereign Debt, Stanford University, mimeo

Yue, Vivian Z., 2005, Sovereign Default and Debt Renegotiation, New York University, mimeo. 


\section{APPENDIX}

Graph 1: The evolution of sovereign spreads for 1973-1981

(compared to BAA-rated US corporations bonds' spread)

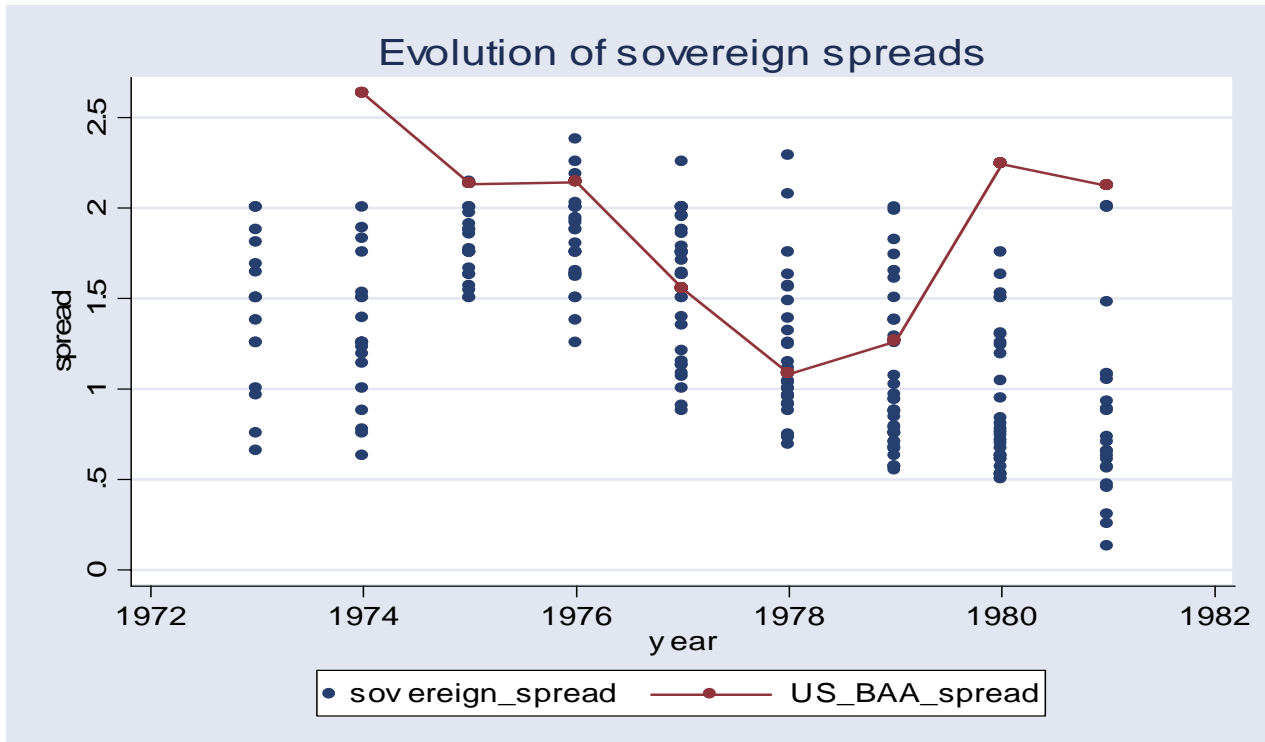

Table 1: The "distant" default variable ${ }^{(a)}$

\begin{tabular}{c|cccc}
\hline Variable: distant default dummy & $\begin{array}{l}\text { Total observations } \\
\text { /countries }\end{array}$ & $\begin{array}{r}\text { Obs. } \\
\text { with 1 }\end{array}$ & Mean & Std. Dev. \\
\hline whole sample & $252 / 46$ & 70 & 0.335 & 0.473 \\
restricted sample & $150 / 37$ & 52 & 0.346 & 0.477 \\
\hline
\end{tabular}

(a): Constructed as a dummy variable for repayment problems on loans for 1940-1970. The dummy takes the value 1 for a repayment problem.

Table 2: The "recent" and "future" default variables (a)

\begin{tabular}{|c|c|c|c|c|c|c|}
\hline Variable & $\begin{array}{l}\text { Total obs. } \\
\text { /countries }\end{array}$ & $\begin{array}{l}\text { Obs. } \\
\text { with } 0\end{array}$ & Mean & $\begin{array}{l}\text { Std. } \\
\text { Dev. }\end{array}$ & Min. & Max. \\
\hline default ${ }^{(b)}$ & $206 / 38$ & 150 & 0.023 & 0.017 & -0.21 & 2 \\
\hline $\begin{array}{l}\text { restricted sample } \\
\text { future default }\end{array}$ & $\begin{array}{l}150 / 37 \\
206 / 38\end{array}$ & $\begin{array}{c}103 \\
43\end{array}$ & $\begin{array}{l}0.009 \\
0.25\end{array}$ & $\begin{array}{c}0.04 \\
1.069\end{array}$ & $\begin{array}{l}-0.006 \\
-1.232\end{array}$ & $\begin{array}{c}0.25 \\
11\end{array}$ \\
\hline restricted sample & $150 / 37$ & 28 & 0.21 & 0.75 & -0.6 & 4.95 \\
\hline
\end{tabular}

(a): Constructed as continuous variables based on arrears data. A zero means no repayment problem.

(b): The indicator adds private arrears for the time t-4 to t-10 and uses linearly decreasing weights. Information refers to the whole sample.

(c): The indicator adds private arrears for 8 years in the future and divides them by the loan amount. Information refers to the whole sample. 
Table 3: Reduced-form estimation: the determinants of the spread ${ }^{\text {(a) }}$

\begin{tabular}{|c|c|c|c|c|}
\hline & Pooled OLS & $\begin{array}{l}\text { Fixed } \\
\text { Fffects }\end{array}$ & $\begin{array}{l}\text { Random } \\
\text { Effects }\end{array}$ & $\begin{array}{c}\text { First } \\
\text { Difference }^{(b)}\end{array}$ \\
\hline & (1) & (2) & (3) & (4) \\
\hline \multirow[t]{2}{*}{ Benchmark yield } & -0.096 & -0.097 & -0.094 & -0.14 \\
\hline & $(-10.73)^{* \star}$ & $(-9.63)^{\star \star}$ & $(-11.42)^{\star \star}$ & $(-2.88)^{\star \star}$ \\
\hline \multirow{2}{*}{$\begin{array}{l}\text { Distant default } \\
(1940-1970)\end{array}$} & 0.222 & - & 0.209 & - \\
\hline & $(2.63)^{\star \star}$ & & $(2.02)^{\star \star}$ & \\
\hline \multirow{2}{*}{$\begin{array}{l}\text { Recent default } \\
\text { (last } 10 \text { years) }\end{array}$} & 1.41 & 2.422 & 1.958 & 1.45 \\
\hline & $(1.69)^{\star \star}$ & $(1.77)^{\star \star}$ & $(1.66)^{\star}$ & $(1.5)^{\star}$ \\
\hline \multirow[t]{2}{*}{ Reserves to imports } & -0.85 & -0.669 & -0.74 & -0.779 \\
\hline & $(-4.9)^{\star \star}$ & $(-3.47)^{\star \star}$ & $(-5.11)^{\star \star}$ & $(-2.88)^{\star \star}$ \\
\hline \multirow[t]{2}{*}{ Exports to GDP } & 0.809 & 1.114 & 0.832 & 1.32 \\
\hline & $(2.52)^{\star \star}$ & $(2.17)^{\star \star}$ & $(2.69)^{\star \star}$ & $(1.95)^{\star \star}$ \\
\hline \multirow[t]{2}{*}{ Savings to GDP } & -0.724 & -0.698 & -0.883 & -0.757 \\
\hline & $(-1.29)$ & $(-1.36)^{\star}$ & $(-2.28)^{\star \star}$ & $(-1.07)$ \\
\hline \multirow[t]{2}{*}{ Repeated borrowings } & -0.179 & -0.473 & -0.364 & -0.575 \\
\hline & $(-0.64)$ & $(-1.63)^{\star}$ & $(-1.33)^{\star}$ & $(-1.71)^{\star \star}$ \\
\hline \multirow{2}{*}{$\begin{array}{l}\text { Countries with arrears } \\
\text { (\% of region total) }\end{array}$} & 0.507 & 0.941 & 0.586 & 5.07 \\
\hline & $(2.1)^{\star \star}$ & $(1.97)^{\star \star}$ & $(2.56)^{\star \star}$ & $(1.41)^{\star}$ \\
\hline \multirow[t]{2}{*}{ Constant } & 2.25 & 2.03 & 2.21 & - \\
\hline & $(11.57)^{\star \star}$ & $(9.13)^{\star \star}$ & $(14.49)^{\star \star}$ & \\
\hline No. of Obs. & 180 & 180 & 180 & 150 \\
\hline$p$ - value $e^{(c)}$ & 0.0000 & 0.0000 & 0.0000 & 0.0000 \\
\hline
\end{tabular}

(a): The t statistics are in parentheses; the standard errors are corrected for clustering at country level. *, ** denote 0.2 and 0.1 significance levels, respectively.

(b): The proportion of countries of arrears (first differenced) is instrumented with its first lag.

(c): $p$ - value of joint significance of the regressors 
Table 4: Structural-form estimation: the determinants of the spread ${ }^{\text {(a) }}$

\begin{tabular}{|c|c|c|c|}
\hline & \multicolumn{3}{|c|}{ Estimation Method } \\
\hline & (1) & (2) & (3) \\
\hline Future default & $\begin{array}{c}0.363 \\
(2.21)^{\star \star}\end{array}$ & $\begin{array}{l}0.389 \\
(2.26)^{\star \star}\end{array}$ & $\begin{array}{l}0.365 \\
(2.24)^{\star \star}\end{array}$ \\
\hline Benchmark yield & $\begin{array}{c}-0.099 \\
(-10.89)^{\star \star}\end{array}$ & $\begin{array}{c}-0.098 \\
(-10.19)^{\star \star}\end{array}$ & $\begin{array}{c}-0.095 \\
(-10.12)^{\star \star}\end{array}$ \\
\hline Recent default & & $\begin{array}{l}4.342 \\
(5.01)^{\star \star}\end{array}$ & $\begin{array}{l}2.438 \\
(3.17)^{\star \star}\end{array}$ \\
\hline Reserves to imports & & & $\begin{array}{l}-0.695 \\
(-2.92)^{\star \star}\end{array}$ \\
\hline \multicolumn{4}{|l|}{ First-stage relevance $^{(\mathrm{c})}$ : } \\
\hline$R^{2}$ for future default & 0.085 & 0.095 & 0.1 \\
\hline F statistics ${ }^{(d)}$ & 12.14 & 5.37 & 4.09 \\
\hline $\begin{array}{r}\text { Anderson Canon. Corr. LR } \\
p-v^{(e)}\end{array}$ & 0.04 & 0.01 & 0.01 \\
\hline \multicolumn{4}{|l|}{$\begin{array}{l}\text { Structural form: } \\
\text { Overidentification test }{ }^{(\mathrm{f})} \text { : }\end{array}$} \\
\hline$p$-value & 0.203 & 0.298 & 0.478 \\
\hline Number of observations & 150 & 150 & 150 \\
\hline
\end{tabular}

(a): The t statistics are in parentheses; the standard errors are corrected for clustering at country level. . *, ** denote 0.2 and 0.1 significance levels, respectively.

(b): The dependent and explanatory variables are first differenced, while the instruments are in general first lags of their levels.

(1) The future default variable is instrumented by the first lag of the following variables: benchmark yield, reserves to imports, savings to GDP, arrears in the region, experience on the market, inflation rate, and recent default.

(2) As (1) but including the recent default (first differenced) as extra exogenous RHS variable.

(3) As (2) but including reserves/imports (first differenced) as extra exogenous RHS variable.

(c): The reduced form regression of the instrumented indicator(s) on the full set of instruments.

(d): From the $\mathrm{F}$ test of the joint significance of the excluded instruments in the first-stage regression.

(e): The Anderson Canonical Correlations Likelihood Ratio test of the null hypothesis that the equation is underidentified.

(f): The Hansen J-statistic 